\title{
Pharmacokinetics of ADS-5102 (Amantadine) Extended Release Capsules Administered Once Daily at Bedtime for the Treatment of Dyskinesia
}

\author{
Robert A. Hauser ${ }^{1}$ Rajesh Pahwa ${ }^{2}$ William A. Wargin ${ }^{3} \cdot$ Cindy J. Souza-Prien ${ }^{4}$. \\ Natalie McClure $^{4} \cdot$ Reed Johnson $^{4} \cdot$ Jack T. Nguyen $^{4} \cdot$ Rajiv Patni $^{4} \cdot$ Gregory T. Went ${ }^{4}$
}

Published online: 18 May 2018

(C) The Author(s) 2018

\begin{abstract}
Background Preclinical and clinical studies suggest amantadine immediate-release (IR) may reduce dyskinesia in Parkinson's disease (PD), although higher doses are associated with increased CNS adverse events (AEs). ADS5102 is an extended release amantadine capsule formulation, designed for once-daily dosing at bedtime (qhs) to provide high concentrations upon waking and throughout the day, with lower concentrations in the evening. The
\end{abstract}

Electronic supplementary material The online version of this article (https://doi.org/10.1007/s40262-018-0663-4) contains supplementary material, which is available to authorized users.

Robert A. Hauser

rhauser@health.usf.edu

Rajiv Patni

rpatni@adamaspharma.com

1 USF Parkinson's Disease and Movement Disorders Center, Parkinson Foundation Center of Excellence, USF Health Byrd Institute, 4001 E. Fletcher Ave, 6th Floor, Tampa, FL 33613, USA

2 Department of Neurology, University of Kansas Medical Center, 3599 Rainbow Boulevard, Mailstop 3042, Kansas City, KS 66160, USA

3 Nuventra Pharma Sciences, 2525 Meridian Parkway, Suite 280, Durham, NC 27713, USA

4 Adamas Pharmaceuticals, Inc, 1900 Powell Street, Suite 750, Emeryville, CA 94608, USA pharmacokinetics (PK) of ADS-5102 were assessed in two phase I studies in healthy subjects, and a blinded, randomized phase II/III dose-finding study in PD patients.

Methods The first phase I study assessed single ADS-5102 doses $(68.5,137$, and $274 \mathrm{mg}$ ) in a crossover design, whereas the second phase I study evaluated ADS-5102 $137 \mathrm{mg}$ for 7 days followed by amantadine IR $81 \mathrm{mg}$ twice daily (or reverse order). In the phase II/III double-blind study, PD patients with dyskinesia were randomized to ADS-5102 (210, 274, or $338 \mathrm{mg})$ or placebo for 8 weeks. Results Single ADS-5102 doses resulted in a slow initial rise in amantadine plasma concentration, with delayed time to maximum concentration (12-16 h). Amantadine plasma concentrations were higher in PD patients versus healthy volunteers. The steady-state profile of once-daily ADS5102 was significantly different from that of twice-daily amantadine IR, such that the two formulations are not bioequivalent. PK modeling suggested the recommended daily ADS-5102 dosage (274 mg qhs) resulted in 1.4- to 2.0-fold higher amantadine plasma concentrations during the day versus amantadine IR.

Conclusions ADS-5102 can be administered once-daily qhs to achieve high amantadine plasma concentrations in the morning and throughout the day, when symptoms of dyskinesia occur. 


\section{Key Points}

ADS-5102 provides a slow initial rise in amantadine plasma concentration and a delayed time to reach maximum concentration, such that once-daily administration at bedtime results in high plasma concentrations upon waking and throughout the day, with lower concentrations in the evening.

Pharmacokinetic (PK) data demonstrate that ADS5102 has a significantly different $\mathrm{PK}$ profile compared with amantadine IR, such that ADS-5102 and amantadine IR are not bioequivalent for the majority of time points throughout the 24-h day.

At the approved recommended dosage of $274 \mathrm{mg}$ once daily, ADS-5102 provided 1.4- to 2.0-fold higher daytime plasma amantadine concentrations compared with amantadine IR administered two or three times daily.

\section{Introduction}

Parkinson's disease (PD) afflicts approximately 1 million people in the US [1]. While levodopa remains the most effective therapy for PD, long-term treatment with levodopa often results in dyskinesia, which is characterized by involuntary movements during waking hours that are nonrhythmic, purposeless, and unpredictable. Approximately $40 \%$ of patients develop dyskinesia after 4-6 years of levodopa treatment, and close to $90 \%$ develop dyskinesia after 10 years of treatment [2]. Dyskinesia has a significant impact on quality of life and is associated with increased risk of falls and healthcare utilization [3, 4].

Amantadine is a low-affinity, uncompetitive NMDA receptor antagonist [5]. A pharmacokinetic (PK)/pharmacodynamic analysis in animal models demonstrated that the $50 \%$ effective amantadine plasma concentration $\left(\mathrm{EC}_{50}\right)$ required to significantly reduce dyskinesia is $\sim 1400 \mathrm{ng} /$ $\mathrm{mL}$ across multiple species, from mice to nonhuman primates, suggesting that similar plasma concentrations are required to reduce dyskinesia in PD patients [6]. Moreover, the $\mathrm{EC}_{50}$ of $1400 \mathrm{ng} / \mathrm{mL}$ (or $\sim 9 \mu \mathrm{M}$ ) is consistent with the known half-maximal inhibitory concentration $\left(\mathrm{IC}_{50}\right)$ of amantadine for inhibition of the NMDA receptor in striatal neurons $(12 \mu \mathrm{M})$ [5]. In small clinical studies, an immediate-release (IR) formulation of amantadine (amantadine IR) has been reported to provide benefit for dyskinesia $[7,8]$; however, the long-term benefit of amantadine IR has been disputed. In one study, PD patients placed on amantadine IR for dyskinesia showed significant benefit for an average of 4.9 months (vs. 1.3 months for placebo), but, in all cases, the benefit lasted $<8$ months [9]. In a more recent study, PD patients who switched to placebo after amantadine IR treatment for a mean of 3.4 years showed significant worsening of dyskinesia at a median of 7 days, suggesting that some patients derived benefit over this duration [10]. Although most patients with PD can tolerate amantadine IR doses of $81-161 \mathrm{mg}$ daily (equivalent to 100-200 mg daily of amantadine hydrochloride [HCl]) (electronic supplementary Table 1), higher doses that may provide greater antidyskinetic benefit are associated with increased frequency of central nervous system (CNS) adverse events (AEs) [7, 11]. Therefore, amantadine IR is typically administered in divided doses, even though its relatively long half-life ( $\sim 17 \mathrm{~h}$ ) might support once-daily dosing [12].

ADS-5102 (amantadine) extended release (ER) capsules (GOCOVRI $^{\mathrm{TM}}$; Adamas Pharma, LLC, Emeryville, CA, USA) is the only FDA-approved treatment for dyskinesia in patients with PD receiving levodopa-based therapy, with or without concomitant dopaminergic medications. The recommended dosage is $274 \mathrm{mg}$ once daily at bedtime. Multiple randomized, placebo-controlled trials have demonstrated that ADS-5102 significantly reduces dyskinesia, with a secondary benefit of reduced OFF time associated with motor complications [13-15].

This report describes the single-dose and steady-state PK of ADS-5102 in healthy volunteers, compared with corresponding PK values for amantadine IR in healthy subjects and the steady-state PK in patients with PD. The mean plasma amantadine concentrations resulting in a significant reduction in dyskinesia in patients with PD are discussed and compared with plasma concentrations observed in healthy volunteers.

\section{Materials and Methods}

Two phase I studies (studies 1 and 2) were conducted to evaluate the PK of ADS-5102 (amantadine) extended release capsules in healthy volunteers. In addition, a phase II/III study (study 3) was conducted in subjects with PD exhibiting dyskinesia. These studies were conducted in accordance with the Declaration of Helsinki and Good Clinical Practice Guidelines. All participating sites received approval from the appropriate Institutional Review Boards and all study participants provided written informed consent prior to enrollment in the study. The studies' designs, inclusion criteria, participant baseline characteristics, and treatment assignments are summarized in Table 1. An overview of the design of each study is provided below. Additional details on study assessments 
Table 1 Overview of ADS-5102 phase I and phase II/III studies

\begin{tabular}{|c|c|c|c|}
\hline $\begin{array}{l}\text { Study } \\
\text { number } \\
\text { and phase } \\
\text { of the trial }\end{array}$ & Title & Study design & Study participants \\
\hline $\begin{array}{l}\text { Study } 1 \\
\text { Phase I }\end{array}$ & $\begin{array}{l}\text { A crossover study to evaluate ADS- } \\
5102 \text { (amantadine) ER capsule dose } \\
\text { proportionality at various levels in } \\
\text { healthy subjects }\end{array}$ & $\begin{array}{l}\text { Single-dose ADS-5102 at morning in } \\
\text { fasted state at dose levels of } 68.5,137 \text {, or } \\
274 \mathrm{mg}\end{array}$ & $\begin{array}{l}30 \text { healthy volunteers; mean age } \\
30.4 \text { years, } 53 \% \text { males; required to be } \\
\text { aged } 18-45 \text { years and weigh } 50-100 \mathrm{~kg} \text {, } \\
\text { with a BMI of } 18.5 \text { to }<30.0 \mathrm{~kg} / \mathrm{m}^{2}\end{array}$ \\
\hline $\begin{array}{l}\text { Study } 2 \\
\text { Phase I }\end{array}$ & $\begin{array}{l}\text { A crossover study to compare single- } \\
\text { dose and steady-state amantadine } \\
\text { pharmacokinetics following oral } \\
\text { administration of ADS-5102 } \\
\text { (amantadine) ER capsules QD with } \\
\text { amantadine IR tablets BID in healthy } \\
\text { subjects }\end{array}$ & $\begin{array}{l}\text { Treatment A: Single-dose ADS-5102 at } \\
\text { night at a dose level of } 137 \mathrm{mg} \text {, followed } \\
\text { by QD dosing of ADS- } 5102 \text { at night for } \\
7 \text { days at a dose level of } 137 \mathrm{mg} \\
\text { Treatment B: Single-dose amantadine IR at } \\
\text { night at a dose level of } 161 \mathrm{mg} \text {, followed } \\
\text { by BID dosing of amantadine IR for } \\
7 \text { days at a dose level of } 81 \mathrm{mg}\end{array}$ & $\begin{array}{l}24 \text { healthy volunteers; mean age } \\
31.8 \text { years, } 79 \% \text { males; required to be } \\
\text { aged } 18-45 \text { years and weigh } 50-100 \mathrm{~kg} \text {, } \\
\text { with a BMI of } 18.5 \text { to }<30.0 \mathrm{~kg} / \mathrm{m}^{2}\end{array}$ \\
\hline $\begin{array}{l}\text { Study } 3 \\
\text { Phase II/ } \\
\text { III }\end{array}$ & $\begin{array}{l}\text { ER amantadine safety and efficacy study } \\
\text { in levodopa-induced dyskinesia } \\
\text { (EASED study) }\end{array}$ & $\begin{array}{l}\text { QHS dosing for a total of } 8 \text { weeks, of one } \\
\text { of four treatments: placebo or ADS- } 5102 \\
210,274 \text {, or } 338 \mathrm{mg}\end{array}$ & $\begin{array}{l}83 \text { PD patients; mean age } 66.0 \text { years, } 54 \% \\
\text { males; required to be aged } 30-85 \text { years, } \\
\text { have a score } \geq 2 \text { on MDS-UPDRS part } \\
4, \text { item } 2, \text { and have } \geq 1 \mathrm{~h} / \text { day of } \text { ON } \\
\text { time with troublesome dyskinesia; } 22 \\
\text { patients were randomized to placebo, } \\
\text { and } 20,21 \text {, and } 20 \text { patients were } \\
\text { randomized to the ADS-5102 dose } \\
\text { levels }\end{array}$ \\
\hline
\end{tabular}

$B I D$ twice daily, BMI body mass index, ER extended release, IR immediate-release, MDS-UPDRS Movement Disorder Society-Unified Parkinson's Disease Rating Scale, $P D$ Parkinson's disease, $Q D$ once daily

and statistical analyses can be found in the electronic supplementary Methods.

\subsection{Study 1}

The purpose of study 1 was to evaluate the plasma PK of amantadine following single-dose administration and to assess dose proportionality after administration of three different doses of ADS-5102 capsules (68.5, 137, or $274 \mathrm{mg}$; equivalent to 85,170 , or $340 \mathrm{mg}$ amantadine $\mathrm{HCl}$, respectively) (electronic supplementary Table 1) in healthy subjects. The study was designed as an open-label, singlecenter, three-period, three-treatment, randomized, crossover study in which 30 healthy subjects were randomly assigned in a 1:1:1:1:1:1 ratio to receive a single dose of each of three treatments in one of six dosing treatment sequences (ABC, $\mathrm{ACB}, \mathrm{BAC}, \mathrm{BCA}, \mathrm{CAB}$, or $\mathrm{CBA}$ ) to balance for potential first-order carryover effects. Each subject was administered a single oral dose of each of the three treatments in the morning in the fasted state, in three separate periods, with a minimum washout period of 7 days between each treatment.

\subsection{Study 2}

Study 2 was an open-label, single-center, single- and multiple-dose, two-period, two-treatment, balanced crossover study designed to evaluate the single-dose and steady-state PK of amantadine following oral administration of ADS-5102 capsules (treatment A) versus amantadine IR tablets (treatment B) in healthy subjects. Twentyfour healthy subjects were randomly assigned $1: 1$ to receive one of two treatment sequences ( $\mathrm{AB}$ or $\mathrm{BA})$, with 12 subjects per treatment sequence. ADS-5102 was administered as one 137-mg capsule at approximately 8:00 pm on day 1 and days 4-10, while amantadine IR was administered as two 81-mg tablets at approximately 8:00 pm on day 1 , and as one $81-\mathrm{mg}$ tablet twice daily at approximately 8:00 pm and 8:00 am, on days 4-10. Food was restricted within $2 \mathrm{~h}$ before or after dosing. A minimum 7-day washout period occurred between the last dose in period 1 and the first dose in period 2 .

\subsection{Study 3}

The design of study 3 (NCT01397422) has been previously described by Pahwa and colleagues [13]. The purpose of that study was to evaluate the efficacy, safety, and tolerability of each of three dose levels of ADS-5102 (210, 274, or $338 \mathrm{mg}$; equivalent to 260,340 , or $420 \mathrm{mg}$ amantadine $\mathrm{HCl}$, respectively) in patients with PD experiencing dyskinesia. Steady-state amantadine concentrations were also measured, and those results are presented here. This study was designed as a multicenter, randomized, double-blind, 
placebo-controlled, four-arm, parallel-group study in which 83 patients at 31 sites were randomly assigned in a 1:1:1:1 ratio to one of four treatments, including placebo. Each patient received an oral dose once daily at bedtime (no earlier than 9:00 pm if possible) for 8 weeks. Samples for amantadine plasma concentration analyses were obtained on day 1 and weeks $1,2,4,6$, and 8 (if the week 6 sample was missed), between 9:00 am and 4:00 pm to correspond with amantadine plateau concentrations.

\subsection{Bioanalyses}

Amantadine concentrations in plasma samples were measured by one of two bioanalytical methods at a central laboratory (PHARMout Laboratories, Inc., Sunnyvale, CA, USA). Both methods were validated according to the US FDA guidance for bioanalytical method validation. A liquid chromatography-tandem mass spectrometry (LC-MS/ MS) method was used to determine amantadine in human dipotassium $\left(\mathrm{K}_{2}\right)$ ethylenediaminetetraacetic acid plasma samples for this study. A $25 \mu \mathrm{L}$ aliquot of internal standard (1-Aminoadamantane- $\mathrm{d}_{6}, 5000 \mathrm{ng} / \mathrm{mL}$ in $50 \%$ methanol) was added to samples and the blank received $50 \%$ methanol in place of the internal standard. Samples were extracted using $300 \mu \mathrm{L}$ acetonitrile:methanol (4:1, volume $[\mathrm{v}]: \mathrm{v})$, and then vortexed and centrifuged. A $25 \mu \mathrm{L}$ aliquot of the supernatant was transferred to a 96-well plate containing $1000 \mu \mathrm{L}$ of $0.1 \%$ formic acid, and then vortexed and centrifuged. A $10 \mu \mathrm{L}$ aliquot of the supernatant was analyzed using LC-MS/MS (API 4000 ${ }^{\mathrm{TM}}$; Applied Biosystems, Foster City, CA, USA), and the eluate from the high-performance liquid chromatography (HPLC) column (Phenomenex Luna ${ }^{\circledR} 5 \mu \mathrm{L}$ PFP (2), $50 \times 2.0 \mathrm{~mm}$; Phenomenex, Torrance, CA, USA) was separated for mass quantification. A mass spectrometer set at mass-to-charge ratios $(\mathrm{m} / \mathrm{z})$ of $152.10>134.90$ and $158.06>140.60$ was used to detect and quantify amantadine and the internal standard, respectively. Data were processed and calculated using an automated data acquisition system (Analyst ${ }^{\circledR}$ 1.4.1; Applied Biosystems, Foster City, CA, USA).

For studies 1 and 2, a similar method was used as described above, but the linear range was modified to accommodate the evaluation of lower doses of ADS-5102. A $300 \mu \mathrm{L}$ aliquot of internal standard (1-Aminoadamantane- $\mathrm{d}_{6}, 50 \mathrm{ng} / \mathrm{mL}$ in acetonitrile:methanol, 4:1, v:v) was added to samples and the blank received $50 \%$ acetonitrile:methanol in place of the internal standard. Samples were vortexed and centrifuged and a $25 \mu \mathrm{L}$ aliquot of the supernatant was transferred to a 96-well plate containing $500 \mu \mathrm{L} 0.1 \%$ formic acid. The plate was then vortexed and centrifuged, and a $20 \mu \mathrm{L}$ aliquot was injected onto the LCMS/MS (API 5000 ${ }^{\mathrm{TM}}$; Applied Biosystems) for analysis and the eluate from the HPLC column (Phenomenex Luna ${ }^{\circledR}$
$5 \mu \mathrm{L}$ PFP (2), $50 \times 2.0 \mathrm{~mm}$, Phenomenex) was separated for mass quantification. A mass spectrometer set at $\mathrm{m} / \mathrm{z}$ of $152.15>134.40$ and $158.17>140.93$ was used to detect and quantify amantadine and the internal standard, respectively. Data were processed and calculated using an automated data acquisition system (Analyst ${ }^{\circledR}$ 1.4.2; Applied Biosystems).

\subsection{Simulations for Renal Impairment}

Model simulations were developed using compartmental modeling with steady-state concentration-time data from study 2 , and elimination rate constants $\left(K_{\mathrm{e}}\right)$ from the literature were used to predict the renal clearances of amantadine over a range of creatinine clearances using Phoenix ${ }^{\circledR}$ WinNonlin ${ }^{\circledR}$ version 6.3 (Pharsight Corporation, a Certara $^{\mathrm{TM}}$ company, St. Louis, MO, USA). The following equation was used:

$C(T)=\frac{F * \text { Dose }}{V\left(K_{\mathrm{a}}-K_{\mathrm{e}}\right)}\left[\exp ^{\left(-K_{\mathrm{e}}\left(T-T_{\mathrm{lag}}\right)\right)}-\exp ^{\left(-K_{\mathrm{a}}\left(T-T_{\mathrm{lag}}\right)\right)}\right]$,

where $C$ was defined as the plasma concentration at a given time $(T), K_{\mathrm{a}}$ as the absorption rate constant, $K_{\mathrm{e}}$ as the elimination rate constant, and $T_{\text {lag }}$ as the lag time for absorption. This equation was fitted to the concentrationtime profiles for each individual following administration of seven once-daily doses of ADS-5102.

\section{Results}

\subsection{Amantadine Pharmacokinetics Following Single Doses of ADS-5102 in Healthy Subjects}

Administration of a single 137-mg ADS-5102 capsule at 8:00 pm (day 1 dosing in study 2) resulted in a mean plasma amantadine concentration-time profile with a lag time for absorption of approximately $3 \mathrm{~h}$, followed by a slow rate of rise in amantadine plasma concentration, resulting in a delayed time to reach maximum concentration ( $T_{\max }$; at approximately $12-16 \mathrm{~h}$ ) (Fig. $1 \mathrm{a}$ and Table 2). The timing of administration of ADS-5102 (day vs. night) resulted in a longer $T_{\max }$ after morning administration $(16 \mathrm{~h})$ compared with nighttime administration (12 h) (Table 2). Other PK parameters (maximum concentration $\left[C_{\max }\right]$, area under the concentration-time curve extrapolated to infinity [AUC ${ }_{\infty}$ ], and half-life $\left[t_{1 / 2}\right]$ ) were similar between morning and nighttime administration. After administration of ADS-5102 capsules in the morning (study 1), dose proportionality was demonstrated for $\mathrm{AUC}_{\infty}$ and $\mathrm{C}_{\max }$ over the dose range of $68.5-274 \mathrm{mg}$ (Fig. 1b and Table 2). 

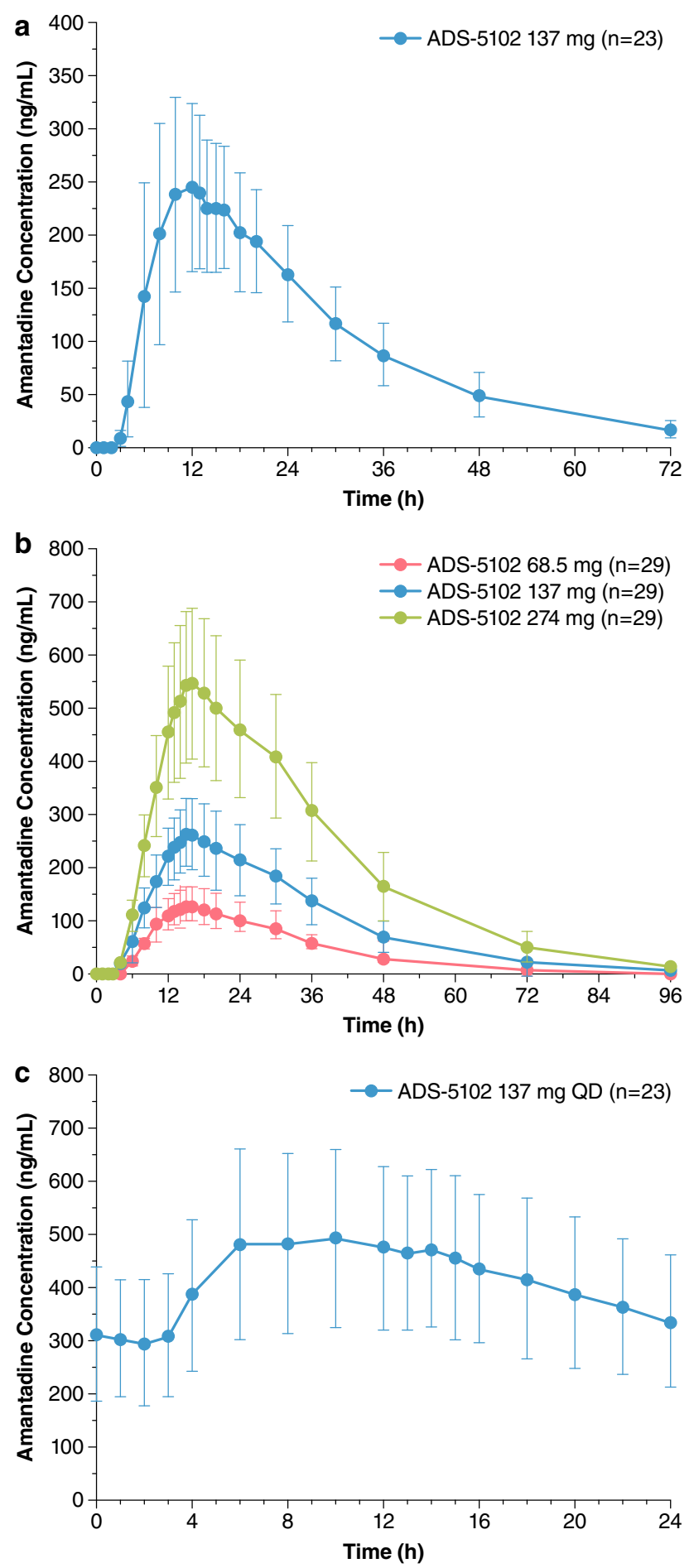

Fig. 1 Single-dose and steady-state concentration-time plots of ADS-5102 in healthy volunteers. a Single-dose profile (study 2); b dose proportionality of single doses (study 1); and c steady-state profile after 7 days of treatment (study 2). Doses are represented as the free-base equivalents of amantadine hydrochloride doses

\subsection{Steady-State PK in Healthy Subjects}

The concentration-time profile for multiple-dose administration of $137 \mathrm{mg}$ ADS-5102 capsules once daily at 8:00 pm showed high plasma concentrations during the day and lower plasma concentrations in the evening (Fig. 1c). The median steady-state $T_{\max }$ of ADS-5102 was approximately $8 \mathrm{~h}$. The elevated amantadine concentrations were observed throughout most of the waking hours, with the lowest concentrations occurring during the first $3 \mathrm{~h}$ after dosing. Steady state was attained by day 8 ( 4 days after the initiation of multiple dosing), as evidenced by comparable predose concentrations collected on days 8,9 , and 10 (geometric means of 317.3, 307.6, and $290.7 \mathrm{ng} / \mathrm{mL}$, respectively). The mean AUC from time 0 to $24 \mathrm{~h}\left(\mathrm{AUC}_{24}\right)$ at steady state $\left(\mathrm{AUC}_{24, \mathrm{ss}}\right)$ for the $137-\mathrm{mg}$ dose administered in the evening was $9947 \mathrm{ng} \cdot \mathrm{h} / \mathrm{mL}$ (Table 3), while $\mathrm{AUC}_{\infty}$ for a comparable single dose was $7489 \mathrm{ng} \cdot \mathrm{h} / \mathrm{mL}$, indicating that a time-dependent decrease in clearance occurs with multiple-dose administration that results in an approximately $20-30 \%$ increase in exposure.

\subsection{ADS-5102 PK and Efficacy in Patients with Parkinson's Disease}

Amantadine is primarily excreted in urine, therefore renal function has the potential to impact amantadine exposure in PD patients. At baseline, the median estimated creatinine clearance in PD patients in study $3\left(74 \mathrm{~mL} / \mathrm{min} / 1.73 \mathrm{~m}^{2}\right.$; range $50-123 \mathrm{~mL} / \mathrm{min} / 1.73 \mathrm{~m}^{2}$ ) was approximately $60 \%$ that of the healthy volunteers in study $2(121 \mathrm{~mL} / \mathrm{min} /$ $1.73 \mathrm{~m}^{2}$; range $84-151 \mathrm{~mL} / \mathrm{min} / 1.73 \mathrm{~m}^{2}$ ). As would be expected, steady-state amantadine plasma concentrations were higher in PD patients than were predicted for healthy individuals. In study 3 , median concentrations in blood samples collected between 9 and $17 \mathrm{~h}$ after ADS-5102 dosing from patients administered $274 \mathrm{mg}$ were approximately $1500 \mathrm{ng} / \mathrm{mL}$ (Fig. 2a). For study 2 data, scaling of the steady-state amantadine plasma $C_{\max }\left(C_{\mathrm{max}, \mathrm{ss}}\right)$ in healthy volunteers for $137 \mathrm{mg}$ ADS-5102 dosing to predict values for the recommended dose of $274 \mathrm{mg}$ yielded $C_{\text {max,ss }}$ values of approximately $1000 \mathrm{ng} / \mathrm{mL}$.

To relate creatinine clearance to amantadine clearance, a relationship between the amantadine $K_{\mathrm{e}}$ and creatinine clearance was established with data from four prior publications [16-19]. Simulations of the plasma amantadine concentration-time profile for ADS-5102 dosing were then conducted using a one-compartment linear model [20] with first-order absorption and first-order elimination, so as to compare the profile for healthy individuals with a creatinine clearance of $121 \mathrm{~mL} / \mathrm{min} / 1.73 \mathrm{~m}^{2}$ and the profile for potential patients with a creatinine clearance of $70 \mathrm{~mL} /$ $\min / 1.73 \mathrm{~m}^{2}$, similar to the value observed in PD patients 
Table 2 Summary of amantadine pharmacokinetic parameters after single doses of ADS-5102 capsules

\begin{tabular}{|c|c|c|c|c|c|c|c|}
\hline \multirow{2}{*}{\multicolumn{2}{|c|}{ Parameter }} & \multicolumn{5}{|l|}{ ADS-5102 capsules } & \multirow{2}{*}{$\begin{array}{l}\text { Amantadine IR tablet } \\
161 \mathrm{mg} \mathrm{pm}^{\mathrm{b}}[n=23]\end{array}$} \\
\hline & & \multicolumn{2}{|c|}{$68.5 \mathrm{mg} \mathrm{am}^{\mathrm{a}}[n=29]$} & $137 \mathrm{mg} \mathrm{am}^{\mathrm{a}}[n=29]$ & $137 \mathrm{mg} \mathrm{pm}^{\mathrm{b}}[n=23]$ & $274 \mathrm{mg} \mathrm{am}^{\mathrm{a}}[n=29]$ & \\
\hline \multicolumn{2}{|l|}{$C_{\max }[\mathrm{ng} / \mathrm{mL}]$} & \multicolumn{2}{|l|}{$141.4(30.4)$} & $272.0(24.9)$ & $266.7(32.7)$ & $558.3(26.1)$ & $464.0(21.1)$ \\
\hline \multicolumn{2}{|l|}{$T_{\max }[\mathrm{h}]^{\mathrm{c}}$} & \multicolumn{2}{|l|}{$15.6(10-20)$} & $16.1(12-24)$ & $11.5(6-20)$ & $15.9(10-20)$ & $3.2(2-6)$ \\
\hline \multicolumn{2}{|l|}{$T_{\text {lag }}[\mathrm{h}]^{\mathrm{c}}$} & \multicolumn{2}{|l|}{$3.6(3-4)$} & $3.0(2-4)$ & $2.3(2-4)$ & $2.4(2-3)$ & NR \\
\hline \multicolumn{2}{|l|}{$\mathrm{AUC}_{\infty}[\mathrm{ng} \cdot \mathrm{h} / \mathrm{mL}]$} & \multicolumn{2}{|l|}{$4254(29.1)$} & $8758(29.7)$ & $7489(29.3)$ & $19193(29.0)$ & $9594(36.0)$ \\
\hline \multicolumn{2}{|l|}{$t_{1 / 2}$} & \multicolumn{2}{|l|}{$12.1(21.7)$} & $12.8(25.3)$ & $14.6(18.5)$ & $12.9(24.8)$ & $14.5(23.5)$ \\
\hline \multicolumn{2}{|l|}{$C_{\max } / \mathrm{dose}$} & \multicolumn{2}{|l|}{$1.66(30.4)$} & $1.60(32.7)$ & $1.57(32.7)$ & $1.64(26.1)$ & $2.32(21.1)$ \\
\hline \multicolumn{2}{|l|}{$\mathrm{AUC}_{\infty} / \mathrm{dose}$} & \multicolumn{2}{|l|}{$50.0(29.1)$} & $51.5(29.7)$ & $44.1(29.3)$ & $56.5(29.0)$ & $48.0(36.0)$ \\
\hline Parameter & \multicolumn{2}{|c|}{ Dose range, $\mathrm{mg}$} & \multicolumn{2}{|c|}{ Estimated slope for $\ln ($ dose $)$} & Standard error & 90\% CI (lower-upper) & Estimated intercept \\
\hline$C_{\max }$ & \multicolumn{2}{|c|}{$68-274$} & \multicolumn{2}{|c|}{0.994} & 0.031 & $0.942-1.046$ & 0.487 \\
\hline $\mathrm{AUC}_{\infty}$ & \multicolumn{2}{|c|}{$68-274$} & 1.081 & & 0.029 & $1.032-1.129$ & 3.502 \\
\hline
\end{tabular}

Data are expressed as mean (\% coefficient of variation) and summary of power analysis for the dose range 68.5-274 mg

$A U C_{\infty}$ area under the concentration-time curve extrapolated to infinity, $C I$ confidence interval, $C_{\max }$ maximum plasma concentration, $I R$ immediate-release, $N R$ not reported, $t_{1 / 2}$ half-life, $T_{\text {lag }}$ lag time, $T_{\max }$ time of observed maximum plasma concentration

${ }^{a}$ From study 1 ; taken at $\sim 8: 30$ am, after an overnight fast

${ }^{\mathrm{b}}$ From study 2 ; taken at $\sim 8: 00 \mathrm{pm}$, approximating the recommended ADS-5102 time of use

${ }^{\mathrm{c}}$ Data are expressed as mean (range)

Table 3 Summary of steadystate pharmacokinetic parameters for ADS-5102 in healthy subjects

\begin{tabular}{|c|c|c|}
\hline Parameter, mean (\%CV) & $\begin{array}{l}\text { ADS-5102 } \\
137 \mathrm{mg} \text { QD } \\
{[n=23]}\end{array}$ & $\begin{array}{l}\text { Amantadine IR } \\
81 \mathrm{mg} \text { BID } \\
{[n=23]}\end{array}$ \\
\hline$C_{\max , \mathrm{ss}}[\mathrm{ng} / \mathrm{mL}]$ & $536.1(31.3)$ & $611.7(27.1)$ \\
\hline$C_{\min , \mathrm{ss}}[\mathrm{ng} / \mathrm{mL}]$ & $284.8(39.6)$ & $366.3(36.4)$ \\
\hline$C_{\text {avg,ss }}[\mathrm{ng} / \mathrm{mL}]$ & $414.4(33.6)$ & $480.5(31.1)$ \\
\hline$T_{\max , \mathrm{ss}}[\mathrm{h}]^{\mathrm{a}}$ & $8.00(4-18)$ & $14.00^{\mathrm{b}}(2-16)$ \\
\hline $\mathrm{AUC}_{24, \mathrm{ss}}[\mathrm{ng} \cdot \mathrm{h} / \mathrm{mL}]$ & 9947 (33.6) & $11531(31.1)$ \\
\hline$C_{\text {max }, \mathrm{ss}} / D[\mathrm{ng} / \mathrm{mL} / \mathrm{mg}]$ & $3.153(31.1)$ & $3.058(27.1)$ \\
\hline$C_{\min , \mathrm{ss}} / D[\mathrm{ng} / \mathrm{mL} / \mathrm{mg}]$ & $1.675(39.6)$ & $1.832(36.4)$ \\
\hline $\mathrm{AUC}_{24, \mathrm{ss}} / D[\mathrm{ng} \cdot \mathrm{h} / \mathrm{mL} / \mathrm{mg}]$ & $58.51(33.6)$ & $57.66(31.1)$ \\
\hline Swing $\left[\left(C_{\mathrm{max}, \mathrm{ss}}-C_{\min , \mathrm{ss}}\right) / C_{\mathrm{min}, \mathrm{ss}}\right]$ & $0.95(34.0)$ & $0.73(29.0)$ \\
\hline Degree of fluctuation $\left[\left(C_{\mathrm{max}, \mathrm{ss}}-C_{\mathrm{min}, \mathrm{ss}}\right) / C_{\mathrm{avg}, \mathrm{ss}}\right]$ & $0.62(24.8)$ & $0.54(22.2)$ \\
\hline Accumulation & $2.52(23.3)$ & $1.82(11.7)$ \\
\hline
\end{tabular}

$\% C V$ percentage coefficient of variation, $A U C_{24, s s}$, area under the plasma concentration-time curve from time 0 to $24 \mathrm{~h}$ at steady state, $A U C_{24, s s} D$ dose-normalized $\mathrm{AUC}_{24, s s}, B I D$ twice daily, $C_{a v g, s s}$ average plasma concentration at steady state, $C_{\max , s s}$ maximum plasma concentration at steady state, $C_{\max , s s} / D$ dosenormalized $\mathrm{C}_{\text {max,ss }}, C_{\text {min,ss }}$ minimum plasma concentration at steady state, $C_{\text {min,ss }} / D$ dose-normalized $\mathrm{C}_{\text {min,ss, }} I R$ immediate-release, $Q D$ once daily, $T_{\max , s s}$ time to maximum plasma concentration at steady state ${ }^{\text {a } D a t a}$ are expressed as median (minimum-maximum)

${ }^{\mathrm{b}}$ The steady-state $T_{\max }$ for amantadine IR occurs $2 \mathrm{~h}$ after the second dose in study 3. Both of the profiles (Fig. 2b) assume an ADS5102 titration schedule of $137 \mathrm{mg}$ once daily for 1 week, escalated to $274 \mathrm{mg}$ once daily in the second week. The profiles associate a reduced creatinine clearance with an increase in the steady-state amantadine $C_{\max }$, which in this case approximated to $1500 \mathrm{ng} / \mathrm{mL}$, suggesting that reduced clearance in elderly PD patients (mean age 66 years in study 3) may result in higher amantadine plasma concentrations than in healthy volunteers.

Efficacy was assessed in a phase II/III study at ADS5102 doses of 210,274 , or $338 \mathrm{mg}$ administered daily at bedtime. ADS-5102 doses of $274 \mathrm{mg}$ and $338 \mathrm{mg}$ showed 

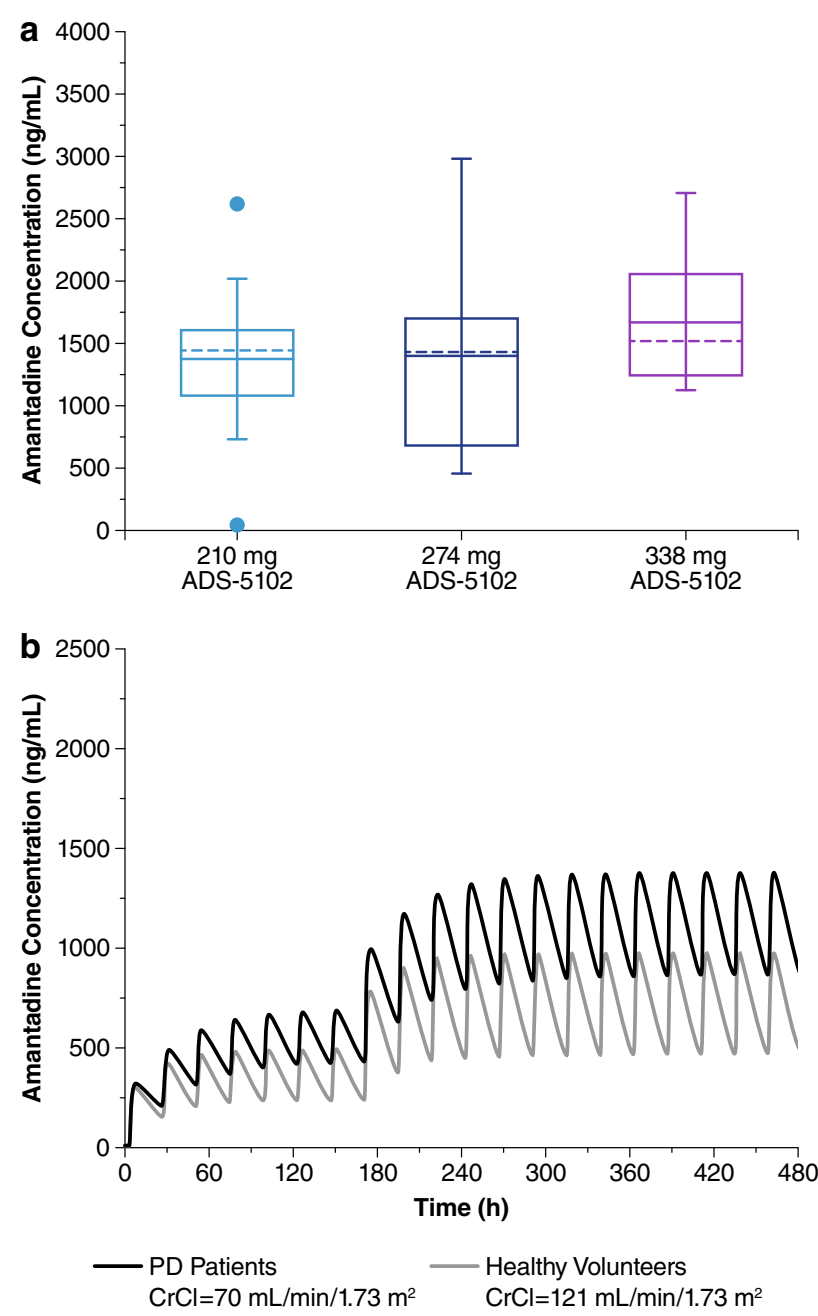

Fig. 2 Steady-state amantadine plasma concentrations in PD patients. a Amantadine concentrations by dose, from study 3. Dashed and solid lines represent the median and arithmetic mean, respectively, in plasma samples obtained on day 1 and weeks $1,2,4$, and 6 or 8 . Boxes represent the 25 th and 75 th percentiles. Whiskers show the lowest and highest value within 1.5-fold the interquartile range. Values falling outside the whiskers are plotted as discrete points. b Simulated amantadine plasma concentrations for PD patients versus healthy individuals receiving ADS-5102. Simulations are based on a titration schedule of $137 \mathrm{mg}$ once daily for 1 week, followed by $274 \mathrm{mg}$ once daily the second week. The simulations based on study 2 and study 3 data were conducted using a one-compartment linear model with first-order amantadine absorption and elimination, and assume a creatinine clearance of $70 \mathrm{~mL} / \mathrm{min} / 1.73 \mathrm{~m}^{2}$ in PD patients and $121 \mathrm{~mL} / \mathrm{min} / 1.73 \mathrm{~m}^{2}$ in healthy persons. $P D$ Parkinson's disease, $\mathrm{CrCl}$ creatinine clearance

significant improvements over placebo in reducing dyskinesia, and mean plasma concentrations at these doses were approximately $1500 \mathrm{ng} / \mathrm{mL}$ in these patients (Fig. 2a) [13]. Rates of CNS AEs were $41 \%$ for placebo and 40, 52, and $55 \%$ for 210, 274, and $338 \mathrm{mg}$ ADS-5102, respectively. Ten subjects (16\%) prematurely discontinued ADS-5102 due to AEs that were CNS-related and most often involved hallucinations. In all treatment groups, and for the majority of affected subjects, the onset of CNS AEs occurred within the first 3 weeks of dosing, when dose titration was taking place for the 274- and 338-mg dose groups. The median amantadine plasma concentration in patients who discontinued due to CNS events was approximately $2100 \mathrm{ng} / \mathrm{mL}$. Sleep-related AEs did not occur at a greater incidence than placebo when ADS-5102 was administered at bedtime in the phase II/III study.

\subsection{Single- and Multidose Comparisons with Amantadine IR}

A comparison of ADS-5102 $137 \mathrm{mg}$ versus amantadine IR $161 \mathrm{mg}$ in healthy subjects demonstrated that the singledose plasma concentration-time profiles of the two formulations are significantly different, as shown in Fig. 3a. After a single oral dose of ADS-5102, a more gradual
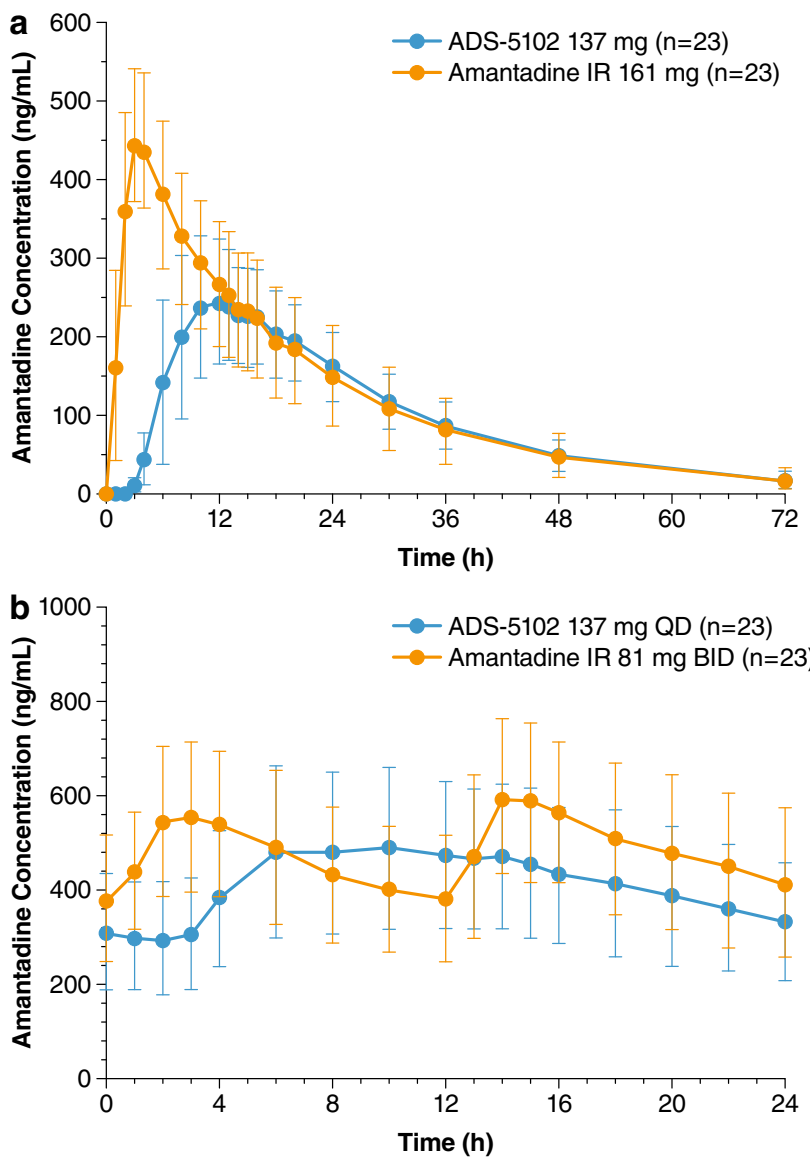

Fig. 3 Comparison of ADS-5102 and amantadine IR in healthy volunteers from study 2. a Linear single-dose plots of mean (SD) plasma amantadine concentration after dosing of $137 \mathrm{mg}$ ADS-5102 compared with $161 \mathrm{mg}$ amantadine IR. b Linear steady-state plots of mean (SD) steady-state plasma amantadine concentration on the seventh day of treatment with $137 \mathrm{mg}$ ADS-5102 once daily $(8: 00 \mathrm{pm})$ compared with $81 \mathrm{mg}$ amantadine IR twice daily (8:00 $\mathrm{pm}$ and 8:00 am). IR immediate-release, $S D$ standard deviation 
increase in the mean plasma amantadine concentration was observed. In comparison, a single oral dose of amantadine IR resulted in a rapid increase in the mean plasma amantadine concentration. The median $T_{\max }$ following ADS5102 administration was delayed compared with that after administration of amantadine IR (12.0 and $3.0 \mathrm{~h}$, respectively). The partial AUC over the first $8 \mathrm{~h}$ after administration of a single dose of ADS-5102 was $8 \%$ of the total amantadine exposure, compared with $28 \%$ for amantadine IR. A half-life $\left(t_{1 / 2}\right)$ of approximately $14.5 \mathrm{~h}$ was observed for both treatments. Administration of single doses of ADS-5102 resulted in high relative bioavailability compared with the amantadine IR formulation, with a dosenormalized $\mathrm{AUC}_{\infty}$ ratio of geometric least squares (LS) means of $93.0 \%$ (90\% confidence interval 87.3-99.0). As expected, dose-normalized $C_{\max }$ was $34 \%$ lower for ADS5102 compared with amantadine IR. These results indicate that ADS-5102 and amantadine IR have different PK characteristics; therefore, dose substitution on a milligram for milligram basis will result in differences in exposure.

After a 3-day washout, study 2 also assessed the steadystate PK of $137 \mathrm{mg}$ ADS-5102 once daily at 8:00 pm versus $81 \mathrm{mg}$ amantadine IR twice daily at 8:00 pm and 8:00 am for 7 days. At steady state, a gradual increase in the mean plasma amantadine concentration following an initial lag was observed after once-daily ADS-5102 administration compared with a more rapid increase in the mean plasma amantadine concentration after the first dose of twice-daily amantadine IR (Fig. 3b). The shape of the elimination phase in the amantadine concentration-time curve was similar after administration of once-daily ADS5102 and the second dose of twice-daily amantadine IR $\left(t_{1 / 2}\right.$ of approximately $16 \mathrm{~h}$, which was only slightly longer than the mean $t_{1 / 2}$ seen after a single dose for both treatments [approximately $14.5 \mathrm{~h}$ ]). At steady state, the $C_{\max , \mathrm{ss}}$, minimum amantadine plasma concentration $\left(\mathrm{C}_{\text {min,ss }}\right)$, and $\mathrm{AUC}_{24, \mathrm{ss}}$ values were lower after $137 \mathrm{mg}$ once-daily ADS5102 than after $81 \mathrm{mg}$ twice-daily amantadine IR (Table 3$)$. The dose-normalized peak $\left(C_{\text {max,ss }} / D\right)$, minimum $\left(C_{\text {min,ss }} / D\right)$, and total $\left(\mathrm{AUC}_{24, \mathrm{ss}} / D\right)$ plasma exposures for amantadine were similar after $137 \mathrm{mg}$ once-daily ADS5102 administration compared with that of $81 \mathrm{mg}$ twicedaily amantadine IR administration (Table 3). However, as shown in electronic supplementary Table 2, ADS-5102 $137 \mathrm{mg}$ administered once daily was not bioequivalent to amantadine IR $81 \mathrm{mg}$ twice daily with respect to overall exposure $\left(\mathrm{AUC}_{24}, C_{\max }\right.$, and $C_{\min }$ ). While the ratio of the geometric LS means of $\mathrm{AUC}_{24}$ and $C_{\max }$ at steady state for $137 \mathrm{mg}$ ADS-5102 once daily and $81 \mathrm{mg}$ amantadine IR twice daily were within 80 and $125 \%$, the ratio for $C_{\min , s s}$ was outside of this range $(77.18 \%$ ) (electronic supplementary Table 2). In addition, the swing and degree of fluctuation were both higher within the ADS-5102 group (Table 3).

To predict plasma concentrations in PD patients based on the expected real-world use of ADS-5102 and amantadine IR, we simulated the steady-state profiles of $274 \mathrm{mg}$ ADS-5102 and $81 \mathrm{mg}$ amantadine IR based on steady-state data from study 2. Simulations for ADS-5102 and amantadine IR were conducted using compartmental analysis to obtain one-compartment PK parameters for individual subjects who had received daily doses of $274 \mathrm{mg}$ ADS5102 or $81 \mathrm{mg}$ twice-daily amantadine IR over 7 days. Compartmental modeling was accomplished using firstorder absorption for amantadine IR and a combination of parallel first-order and zero-order absorption for ADS5102. The latter model provided better fits to the ADS5102 concentration-time profiles for individual subjects, consistent with the fact that ADS-5102 is an extended release formulation and, as such, there may be greater variance in absorption over time between individuals. A correction factor of 1.6 was applied to account for the reduced clearance in $\mathrm{PD}$ patients $\left(121 \mathrm{~mL} / \mathrm{min} / 1.73 \mathrm{~m}^{2}\right.$ in healthy volunteers vs. $74 \mathrm{~mL} / \mathrm{min} / 1.73 \mathrm{~m}^{2}$ in PD patients). Since the $274 \mathrm{mg}$ once-daily dose of ADS-5102 at bedtime is the recommended dose for the treatment of dyskinesia based on randomized controlled trials, dosing was simulated at 10:00 pm [13-15]. For amantadine IR, we simulated the steady-state profile for two of the more common real-world dosing regimens: $81 \mathrm{mg}$ administered at 8:00 am and 4:00 pm, and $81 \mathrm{mg}$ administered at 8:00 am, 12:00 pm, and 4:00 pm; due to the known sleep-related AEs associated with amantadine IR [21], some guidances recommend that the last dose of amantadine IR be administered before 4:00 pm [22]. These amantadine IR regimens are consistent with a retrospective analysis of patient insurance claims from Symphony Health Solutions which demonstrated that, in levodopa-treated patients who were treated with amantadine IR adjunctively, $\sim 85 \%$ of patients were prescribed doses of $161 \mathrm{mg} /$ day (equivalent to $200 \mathrm{mg}$ amantadine $\mathrm{HCl}$ ) or lower, compared with $\sim 15 \%$ who were prescribed $242 \mathrm{mg} /$ day (equivalent to $300 \mathrm{mg}$ amantadine $\mathrm{HCl}$ ) or higher [23]. Concentrations of amantadine from both ADS-5102 and amantadine IR were simulated using the lower clearance estimate observed in PD patients in study $3\left(74 \mathrm{~mL} / \mathrm{min} / 1.73 \mathrm{~m}^{2}\right)$.

As shown in Fig. 4, the simulated steady-state profile of ADS-5102 administered at 10:00 pm in PD patients showed a $C_{\max }$ of $1690 \mathrm{ng} / \mathrm{mL}$, consistent with the mean concentration observed in PD patients in the phase II/III trial, with high concentrations in the morning and throughout the waking hours. Importantly, the $C_{\max }$ for ADS-5102 $274 \mathrm{mg}$ once daily is approximately 1.7-fold higher than the $C_{\max }$ obtained with $81 \mathrm{mg}$ amantadine IR twice daily $(967 \mathrm{ng} / \mathrm{mL})$. With three-times-daily 

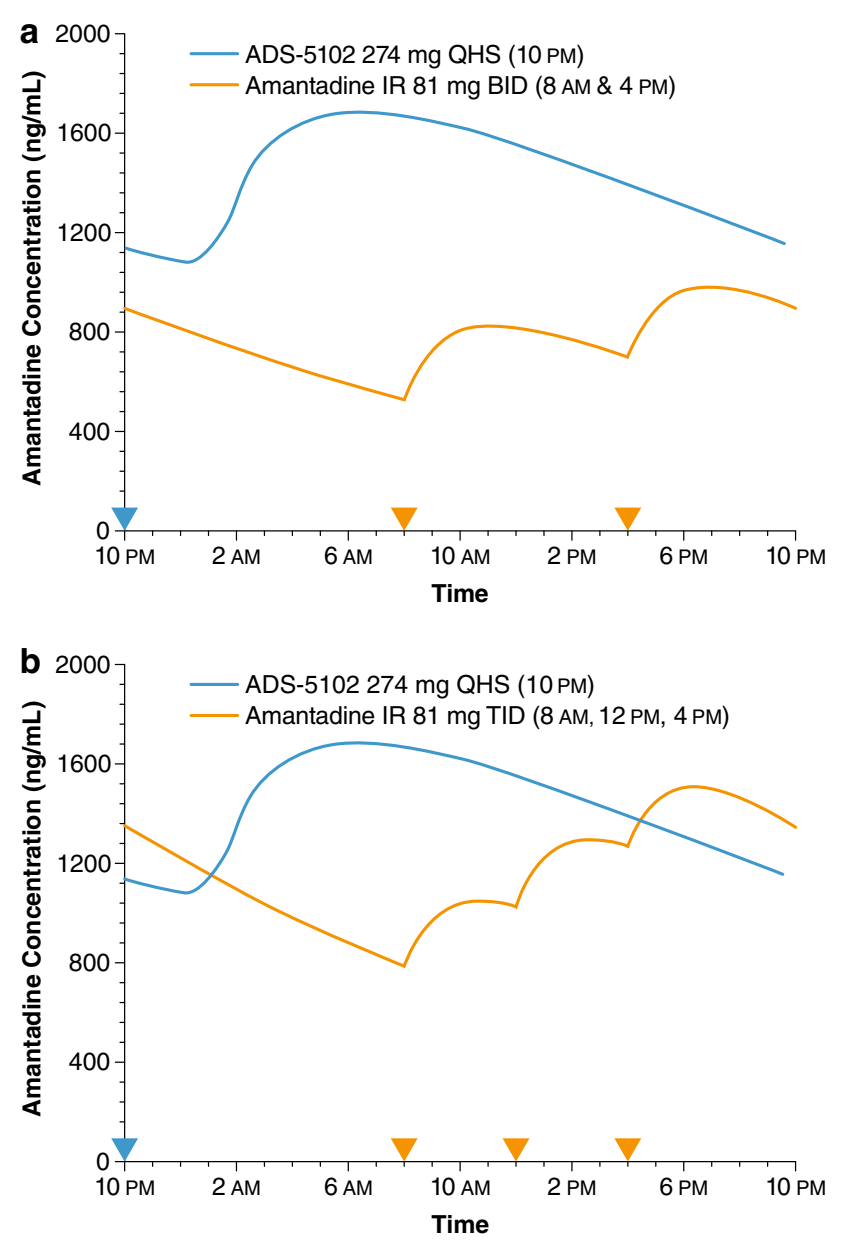

Fig. 4 Simulations of real-world use of ADS-5102 and amantadine IR in PD patients, based on compartmental analysis of 7-day treatment in study 2. a Linear steady-state plots of mean amantadine plasma concentration for $274 \mathrm{mg}$ ADS-5102 (10:00 pm) and $81 \mathrm{mg}$ amantadine IR twice daily (8:00 am and 4:00 pm). b Linear steadystate plots of mean amantadine plasma concentration for $274 \mathrm{mg}$ ADS-5102 (10:00 pm) and $81 \mathrm{mg}$ amantadine IR three times daily $(8: 00 \mathrm{am}, 12: 00 \mathrm{pm}$, and 4:00 pm). Arrowheads indicate the timing of drug administration for ADS-5102 (blue) and amantadine IR (orange). Validation of simulations is shown in electronic supplementary Fig. 1. IR immediate-release, $P D$ Parkinson's disease

administration of amantadine IR, maximum plasma concentrations $(1500 \mathrm{ng} / \mathrm{mL})$ approached those attained with ADS-5102, but this occurred only in the evening, after $5: 00 \mathrm{pm}$. The average daytime concentration (from 6:00 am to 6:00 pm) for ADS-5102 $(1536 \mathrm{ng} / \mathrm{mL})$ is 2.0 fold to 1.4-fold higher than that attained by $81 \mathrm{mg}$ amantadine IR two to three times daily $(751 \mathrm{ng} / \mathrm{mL}$ and $1125 \mathrm{ng} / \mathrm{mL}$, respectively).

Using a stringent analysis to compare the bioequivalence of ADS-5102 administered at 10:00 pm with amantadine IR administered twice daily (8:00 am and 4:00 pm) and three times daily $(8: 00 \mathrm{am}, 12: 00 \mathrm{pm}$, and 4:00 pm), point-to-point comparisons of the ratio of the plasma concentration at each time point, the ratio of the AUC from time zero to each plasma sampling time point (partial $\mathrm{AUC}_{\mathrm{p}}$ ), and the ratio of the AUC from one plasma sampling time point to the next (partial $\mathrm{AUC}_{\mathrm{t} 1-\mathrm{t} 2}$ ) was conducted using the simulated steady-state profiles (Fig. 5). These results demonstrated that $274 \mathrm{mg}$ ADS-5102 once daily at 10:00 pm, and $81 \mathrm{mg}$ amantadine IR twice daily, were not equivalent for any of the time points throughout the 24-h day $(0 \%$ of the time points were within the $80-125 \%$ range) (Fig. 5a-c). Importantly, the ratio of the plasma concentrations between ADS-5102 and amantadine IR was greatest between 8 and $10 \mathrm{~h}$ post the ADS-5102 dose (Fig. 5a), which is expected to occur between 6:00 am and 8:00 am when patients would be waking, prior to their first levodopa dose of the day. When compared with $81 \mathrm{mg}$ amantadine IR three times daily, comparison of the point-to-point ratios between ADS-5102 and amantadine IR were still not equivalent for the majority of the day, with only $31-35 \%$ of the time points falling within the $80-125 \%$ range, with the greatest differences occurring in the morning.

\section{Discussion}

For patients with PD who experience dyskinesia, symptoms of motor complications (dyskinesia and OFF) typically occur in the morning and throughout the waking day when patients are taking levodopa [13]. As an extended release formulation of amantadine, ADS-5102 was designed to have a reduced rate of initial rise and a delayed $T_{\max }$, such that once-daily administration at bedtime results in peak concentrations in the morning when the patient awakens. This profile also provides high plasma concentrations through the waking day to provide benefit for dyskinesia and OFF time (Fig. 4).

The present studies evaluated the PK of amantadine following ADS-5102 administration in healthy volunteers and PD patients, and provided comparisons with amantadine IR as the reference product. For amantadine IR, the findings are consistent with those reported by other researchers in healthy persons taking various amantadine IR regimens [16-18]. For ADS-5102, the findings versus amantadine IR were obtained (in study 2) using the highest dose strength of ADS-5102 capsules $(137 \mathrm{mg}$ ), administered once (for single-dose PK assessment) and then oncedaily (for steady-state PK assessment). However, the recommended dose of ADS-5102 for the treatment of dyskinesia in PD patients is $274 \mathrm{mg}$ (two 137-mg capsules), taken once daily at bedtime. Extrapolation of the PK data to $274 \mathrm{mg}$ is warranted in order to fully appreciate the PK profile of ADS-5102 in real-world use. 

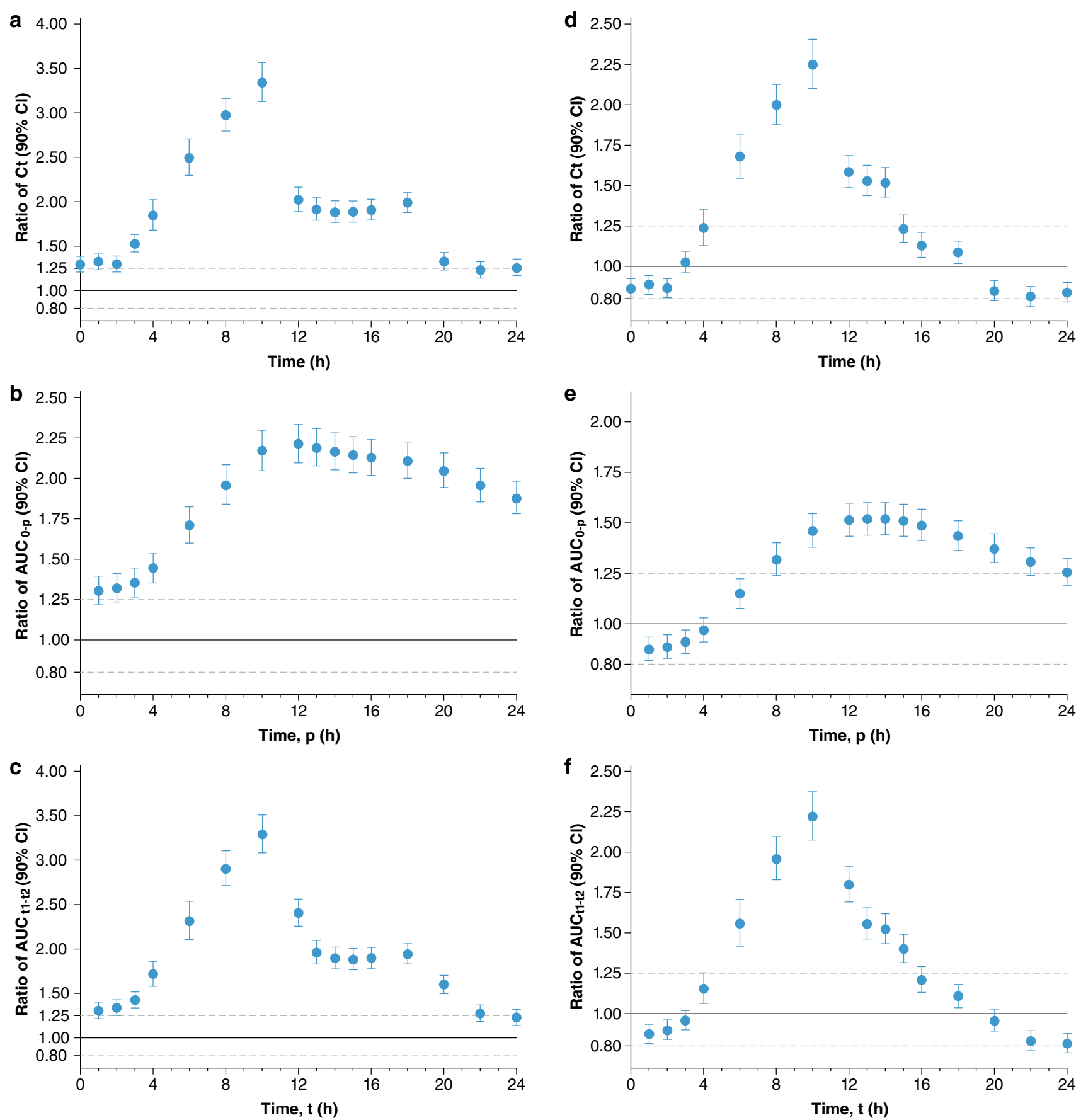

Fig. 5 Time-point to time-point comparisons of ADS-5102 and amantadine IR at steady state based on real-world simulations. The comparisons are $274 \mathrm{mg}$ ADS-5102 (10:00 pm) versus $81 \mathrm{mg}$ amantadine IR twice daily (at 8:00 am and 4:00 pm, left charts) and $274 \mathrm{mg}$ ADS-5102 (10:00 pm) versus $81 \mathrm{mg}$ amantadine IR three times daily (at 8:00 am, 12:00 pm, and 4:00 pm, right charts). The values displayed are the ratio of plasma amantadine

The PK data reported here demonstrate that ADS-5102 has a significantly different shape to its PK profile than amantadine IR. The difference in the PK profile is demonstrated by the difference in the steady-state plasma

concentration, $C_{\mathrm{t}}(\mathbf{a}, \mathbf{d})$; partial AUC from time 0 to each sampling time point, $\mathrm{AUC}_{\mathrm{p}}(\mathbf{b}, \mathbf{e})$; and partial $\mathrm{AUC}$ from one plasma sampling time point to the next, $\mathrm{AUC}_{\mathrm{t} 1-\mathrm{t} 2}(\mathbf{c}, \mathbf{f})$. In each chart, error bars represent $90 \%$ confidence intervals, and dashed lines delineate ratios with confidence intervals between 80 and $125 \%$. IR immediaterelease, $A U C$ area under the concentration-time curve

concentration-time curves between ADS-5102 and amantadine IR (Fig. 3), wherein ADS-5102 exhibited a relatively smooth concentration-time curve with lower plasma concentration for the first $4 \mathrm{~h}$ postdose and gradually rising 
to reach a peak at $8 \mathrm{~h}$ postdose. When administered at bedtime, the ADS-5102 profile resulted in high plasma concentrations upon waking and throughout the day, with lower concentrations in the evening. In contrast, amantadine IR administered two to three times daily is characterized by low concentrations upon waking, with higher concentrations in the evening into the night, potentially contributing to sleep-related AEs. The difference in the PK profiles is further supported by the lack of bioequivalence between ADS-5102 and amantadine IR with respect to the rate and extent of absorption. Moreover, at the recommended dosage of $274 \mathrm{mg}$ once daily, ADS-5102 provided 2.0- to 1.4-fold higher daytime plasma concentrations compared with amantadine IR administered two or three times daily, respectively (Fig. 4). The fact that the largest difference in amantadine concentrations between ADS5102 and amantadine IR was in the morning may be clinically relevant because it coincides with the timing of a PD patient's first levodopa dose.

Data from animal and human studies indicate a good concentration-effect relationship for amantadine in reducing dyskinesia $[6,7]$. While scaling of the dose of ADS-5102 to the recommended dose of $274 \mathrm{mg}$ in healthy volunteers indicated that the $C_{\max , s s}$ would be approximately $1000 \mathrm{ng} / \mathrm{mL}$, higher amantadine concentrations were achieved in PD patients $(\sim 1500 \mathrm{ng} / \mathrm{mL})$ in study 3, which approximated the $\mathrm{EC}_{50}$ for the reduction in dyskinesia observed in rodents and nonhuman primates $(\sim 1400 \mathrm{ng} / \mathrm{mL})$. Since elderly people often have reduced renal function [24], and since the majority of PD patients are diagnosed at age 60 years or older [25], the higher plasma concentrations observed in PD patients in study 3 are likely to represent the real exposure of amantadine in the larger PD population after treatment with $274 \mathrm{mg}$ ADS-5102.

In three placebo-controlled clinical studies, ADS-5102 was shown to be effective at reducing dyskinesia and OFF time in patients with PD who experience dyskinesia [13-15]. In all three studies, the reduction in dyskinesia was significant at the first visit ( 2 weeks) and was durable for up to 24 weeks. Moreover, benefits for dyskinesia and OFF time were observed throughout the waking day $[14,15]$. While dose-dependent increases in sleep-related AEs were reported in early studies with amantadine IR in PD patients [21] and healthy elderly volunteers [26], the incidence of sleep-related AEs (e.g., insomnia) was low in the ADS-5102 clinical program despite the high dose of amantadine used. In the clinical program, the most common adverse reactions were hallucination, dizziness, dry mouth, peripheral edema, constipation, fall, and orthostatic hypotension [13-15]. The low rate of sleep-related AEs in controlled studies with ADS-5102 may be due in part to the tempered initial rise in amantadine concentrations during the first part of the night, which may decrease the occurrence of sleep-related AEs. Because of the differences in the PK profiles of ADS-5102 and amantadine IR, it cannot be assumed that amantadine IR can provide equivalent efficacy and tolerability to that demonstrated with ADS-5102. Thus, the robust clinical efficacy for reducing dyskinesia and OFF time, and the favorable tolerability of ADS-5102, may be in part due to its unique PK profile.

Acknowledgements The authors would like to thank Gayatri Sathyan for the PK analyses. Under the direction of the authors, editorial assistance was provided by The Curry Rockefeller Group, LLC, which was funded by Adamas Pharmaceuticals, Inc.

\section{Compliance with Ethical Standards}

Funding Funding for these studies was provided by Adamas Pharmaceuticals, Inc.

Conflicts of interest Robert A. Hauser is supported in part by a Center of Excellence grant from the National Parkinson Foundation. He received payment from Adamas Pharmaceuticals for participating as a Steering Committee member, and reports consulting fees from Teva Pharmaceuticals, UCB BioSciences, AbbVie, Novartis, Biotie Therapies, Lundbeck, Pfizer, Allergan Neuroscience, Neurocrine Biosciences, Chelsea Therapeutics, Auspex Pharmaceuticals, Acadia Pharmaceuticals, Michael J. Fox Foundation, GLG, AstraZeneca, Acorda Therapeutics, Impax Pharmaceuticals, Cynapsus Therapeutics, US WorldMeds, Neuropore, and Prexton Therapeutics. $\mathrm{He}$ is employed by the University of South Florida (Florida). Rajesh Pahwa is receiving, or has received, honoraria or payments for consulting from AbbVie, Acadia, Acorda, Adamas, Sunovion, Impax, Lundbeck, Neurocrine, Sage, St. Jude Medical, Teva Neuroscience, UCB, US WorldMeds, and Global Kinetics, and has also received research grants from Acadia, Acorda, Adamas, Avid, Biotie, Boston Scientific, Civitas, Cynapsus, Kyowa, NIH/NINDS, NPF, Pfizer, and PSG/University of Rochester. He has served on the Data Monitoring Committee for Ionis and has received personal compensation as the Co-Editor-in-Chief of the International Journal of Neuroscience. William Wargin is an employee of Nuventra Pharma Sciences. Cindy Souza-Prien, Rajiv Patni, Reed Johnson, Jack Nguyen, and Gregory T. Went are employees of, and own stock in, Adamas Pharmaceuticals. Natalie McClure was employed by Adamas Pharmaceuticals at the time this research was undertaken, and owns stock in Adamas.

Ethics approval All procedures performed in studies involving human participants were in accordance with the ethical standards of the institutional and/or national research committee and with the 1964 Helsinki declaration and its later amendments or comparable ethical standards.

Open Access This article is distributed under the terms of the Creative Commons Attribution-NonCommercial 4.0 International License (http://creativecommons.org/licenses/by-nc/4.0/), which permits any noncommercial use, distribution, and reproduction in any medium, provided you give appropriate credit to the original author(s) and the source, provide a link to the Creative Commons license, and indicate if changes were made. 


\section{References}

1. Van Den Eeden SK, Tanner CM, Bernstein AL, Fross RD, Leimpeter A, Bloch DA, et al. Incidence of Parkinson's disease: variation by age, gender, and race/ethnicity. Am J Epidemiol. 2003;157(11):1015-22.

2. Ahlskog JE, Muenter MD. Frequency of levodopa-related dyskinesias and motor fluctuations as estimated from the cumulative literature. Mov Disord. 2001;16(3):448-58.

3. Hechtner MC, Vogt T, Zollner Y, Schroder S, Sauer JB, Binder $\mathrm{H}$, et al. Quality of life in Parkinson's disease patients with motor fluctuations and dyskinesias in five European countries. Parkinsonism Relat Disord. 2014;20(9):969-74.

4. Suh DC, Pahwa R, Mallya U. Treatment patterns and associated costs with Parkinson's disease levodopa induced dyskinesia. J Neurol Sci. 2012;319(1-2):24-31.

5. Parsons CG, Quack G, Bresink I, Baran L, Przegalinski E, Kostowski W, et al. Comparison of the potency, kinetics and voltagedependency of a series of uncompetitive NMDA receptor antagonists in vitro with anticonvulsive and motor impairment activity in vivo. Neuropharmacology. 1995;34(10):1239-58.

6. Brigham EF, Johnston TH, Brown C, Holt JDS, Fox SH, Hill MP et al. Pharmacokinetic/pharmacodynamic correlation analysis of amantadine for levodopa-induced dyskinesia. JPET. 2018. (Under Review).

7. Verhagen Metman L, Del Dotto P, van den Munckhof P, Fang J, Mouradian MM, Chase TN. Amantadine as treatment for dyskinesias and motor fluctuations in Parkinson's disease. Neurology. 1998;50(5):1323-6.

8. Goetz CG, Stebbins GT, Chung KA, Hauser RA, Miyasaki JM, Nicholas AP, et al. Which dyskinesia scale best detects treatment response? Mov Disord. 2013;28(3):341-6.

9. Thomas A, Iacono D, Luciano AL, Armellino K, Di Iorio A, Onofrj M. Duration of amantadine benefit on dyskinesia of severe Parkinson's disease. J Neurol Neurosurg Psychiatry. 2004;75(1):141-3.

10. Ory-Magne F, Corvol JC, Azulay JP, Bonnet AM, Brefel-Courbon C, Damier P, et al. Withdrawing amantadine in dyskinetic patients with Parkinson disease: the AMANDYSK trial. Neurology. 2014;82(4):300-7.

11. Hayden FG, Hoffman HE, Spyker DA. Differences in side effects of amantadine hydrochloride and rimantadine hydrochloride relate to differences in pharmacokinetics. Antimicrob Agents Chemother. 1983;23(3):458-64.

12. Symmetrel (amantadine hydrochloride, USP) [prescribing information]. Chadds Ford, PA: Endo Pharmaceuticals Inc. 2009. Available online: https://www.accessdata.fda.gov/drugsatfda_ docs/label/2009/016023s041,018101s016lbl.pdf. Accessed 3 May 2018.

13. Pahwa R, Tanner CM, Hauser RA, Sethi K, Isaacson S, Truong $\mathrm{D}$, et al. Amantadine extended release for levodopa-induced dyskinesia in Parkinson's disease (EASED Study). Mov Disord. 2015;30(6):788-95.

14. Pahwa R, Tanner CM, Hauser RA, Isaacson SH, Nausieda PA, Truong DD, et al. ADS-5102 (Amantadine) Extended-release capsules for levodopa-induced dyskinesia in Parkinson disease (EASE LID Study): a randomized clinical trial. JAMA Neurol. 2017;74(8):941-9.

15. Oertel W, Eggert K, Pahwa R, Tanner CM, Hauser RA, Trenkwalder C, et al. Randomized, placebo-controlled trial of ADS5102 (amantadine) extended-release capsules for levodopa-induced dyskinesia in Parkinson's disease (EASE LID 3). Mov Disord. 2017;32(12):1701-9.

16. Wu MJ, Ing TS, Soung LS, Daugirdas JT, Hano JE, Gandhi VC. Amantadine hydrochloride pharmacokinetics in patients with impaired renal function. Clin Nephrol. 1982;17(1):19-23.

17. Horadam VW, Sharp JG, Smilack JD, McAnalley BH, Garriott JC, Stephens MK, et al. Pharmacokinetics of amantadine hydrochloride in subjects with normal and impaired renal function. Ann Intern Med. 1981;94(4 Pt 1):454-8.

18. Aoki FY, Sitar DS, Ogilvie RI. Amantadine kinetics in healthy young subjects after long-term dosing. Clin Pharmacol Ther. 1979;26(6):729-36.

19. Aoki FY, Stiver HG, Sitar DS, Boudreault A, Ogilvie RI. Prophylactic amantadine dose and plasma concentration-effect relationships in healthy adults. Clin Pharmacol Ther. 1985;37(2):128-36.

20. Gibaldi M, Perrier D. One compartmental model. In: Gibaldi M, Perrier D, editors. Pharmacokinetics. Second ed. Marcel Dekker, Inc.; 1982. p. 1-42.

21. Parkes JD, Zilkha KJ, Marsden P, Baxter RC, Knill-Jones RP. Amantadine dosage in treatment of Parkinson's disease. Lancet. 1970;1(7657):1130-3.

22. Amantadin STADA ${ }^{\circledR} 100 \mathrm{mg}$ Tabletten (amantadine hydrochloride). [Information for Users-In German]. Bad Vilbel, Germany: STADAPHARM GmbH. 2015. Available online: https://www. apotheken-umschau.de/Medikamente/Beipackzettel/AMANTAD IN-STADA-100-mg-Tabletten-8818243.html. Accessed 3 May 2018.

23. Navarro R, Whangbo A, Pahwa R, Isaacson S, Schmidt P, Went GT. An assessment of the persistence and medication possession ratio of adjunctive treatments to levodopa in patients with Parkinson's disease (PD). ISPOR 22nd Annual International Meeting, 20-24 May 2017; Boston, MA.

24. Papaioannou A, Ray JG, Ferko NC, Clarke JA, Campbell G, Adachi JD. Estimation of creatinine clearance in elderly persons in long-term care facilities. Am J Med. 2001;111(7):569-73.

25. Pagano G, Ferrara N, Brooks DJ, Pavese N. Age at onset and Parkinson disease phenotype. Neurology. 2016;86(15):1400-7.

26. Hayden FG, Gwaltney JM Jr, Van de Castle RL, Adams KF, Giordani B. Comparative toxicity of amantadine hydrochloride and rimantadine hydrochloride in healthy adults. Antimicrob Agents Chemother. 1981;19(2):226-33. 